Науковий вісник НлТУ України

Scientific Bulletin of UNFU

http://nv.nltu.edu.ua

https://doi.org/10.15421/40280211

Article received 21.03.2018 p.

Article accepted 29.03.2018 p.

удк 634.746:635.9
ISSN 1994-7836 (print)

ISSN 2519-2477 (online)

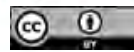

$@ \bowtie$ Correspondence author

O. V. Reshetiuk

o.reshetyuk@chnu.edu.ua

О. В. Решетюк ${ }^{1}$, А. Б. Філіпенко

${ }^{1}$ Чернівецький національний університет ім. Юрія Федьковича, м. Чернівиі, Украйна

${ }^{2}$ Східноєвропейський національний університет ім. Лесі Украӥнки, м. Луцьк, Украйна

\title{
БАРБАРИСИ (РІД ВЕRВERIS L.) У ДЕКОРАТИВНОМУ ОЗЕЛЕНЕННІ
}

Визначено особливості органогенезу та онтогенезу 29 видів роду Berberis L. у культурі (Чернівецька обл.), виявлено відмінності у проходженні окремих вікових періодів розвитку та загальну тривалість онтогенезу. На основі фенологічних спостережень виділено специфічні особливості їхнього сезонного розвитку залежно від географічного походження. Вегетаційний період триває з квітня до середини жовтня (190-200 днів), квітування - впродовж травня, достигання плодів - 3 липня до кінця серпня. Встановлено потенційні можливості культивованих барбарисів у фазах квітування (нектаропродуктивність - до 60-80 кг/га на добу) та плодоношення (з 40-50 до 350-420 плодів/пог.м пагона). Доведено, що високі показники та якість нектару і плодів можна успішно використати в господарських цілях (бджільництво, харчування, лікування тощо): нектаропродуктивність таких культур забезпечить урожай 2,1-2,5 т/га меду з унікальними смаковими та цілющими властивостями, а також до 3,5-4,2 т/га сировини лікарського та харчового призначення. Проаналізовано зимостійкість барбарисів, яка не опускається нижче I-II балів (у B. dasystachhya і B. arthobotrys пагони можуть підмерзати вище від снігового покриву). Вивчено репродуктивну здатність цих видів, які легко розмножуються насінням (краще його висівати восени). За результатами виконаних досліджень виділено 3 групи видів, перспективних для культивування у кліматичних умовах Буковини, та розроблено рекомендації щодо впровадження барбарисів у декоративні посадки.

Ключові слова: інтродукція; початок вегетації; культивування; зимостійкість; декоративність.

Вступ. Рід Berberis L. з родини Berberidaceae Juss. налічує близько 175 видів і $\epsilon$ надзвичайно різноманітним, представлений різними життєвими формами (Vasyleva \& Shreter, 1970; Davlatov, 2004). Серед представників роду $є$ дерева, чагарники і навіть багаторічні трави (Berberis graminea Ahrendt, Китай). Відомі вічнозелені і листопадні види, що зростають в різних екологічних умовах. Барбариси поширені в Євразії, Північній Африці, Північній та Південній Америці, Середній Азії, на Кавказі, переважно в гірських районах. Центром родового ареалу є китайсько-тибетський рослинно-кліматичний регіон, де виявлено найбільшу кількість видового розмаїття цих рослин (Davlatov, 2004; Slyzyk, 1964). В Україні у природному стані відомо тільки один барбарис звичайний (Berberis vulgaris L.), який трапляється у Кримських горах, а також зрідка в долинах Дніпра та Дністра (Fylypenko, 1979). Цілющі властивості барбарисів були відомі ще нашим предкам. Зокрема, в "Ассурбаніпаловій бібліотеці" (V-IV ст. до н.е.) згадку про них знаходимо на глиняних дощечках серед описання інших лікарських рослин того часу (Oleksevych, 1972; Рalamarchuk \& Bondarenko, 1974). Коли у XVI ст. барбариси почали інтродукувати з арабських країн в Свропу разом 3 іншими видами декоративних та лікарських рослин, вони з'явились в парках Великобританії, Франції, а пізніше навіть у Швеції та Норвегії. Їх масово культивували у приватних колекціях і великих ботанічних садах, використовуючи у солітерних і групових посадках та для формування живоплотів (вільноростучих, стрижених), низькорослі ж види - були окрасою кам'янистих гірок чи мали вигляд бордюрів. Але наприкінці XVII ст. було встановлено причетність барбарисів до поширення небезпечних для злакових культур іржастих грибів, що різко скоротило популярність барбарисів у декоративному озелененні та в складі популярних лікарських культур (Fylypenko, 1979). Зараз у колекціях ботанічних садів України налічується близько 80 видів барбарисів, хоч у декоративному озелененні трапляються переважно декілька видів і форм цих рослин (Наlushko, 1997; Yakobchuk \& Kolesnichenko, 2013).

Матеріали і методи дослідження. Мета роботи встановити перспективні види роду Berberis для використання в декоративному озелененні. Об'єкти досліджень - 29 видів барбарисів різного географічного походження, культивовані в умовах ботанічного саду ЧНУ і в інших колекціях на території Чернівецької області. Вивчали особливості онтогенезу та сезонного розвитку видів, особливу увагу приділяли аналізу умов зростання барбарисів в умовах культури, а також агротехніці розмноження та вирощування цих рослин. Методи дослідження: загальнобіологічні, експедиційні, візуальні. Спостереження проводили впродовж 2005-

\section{Інформація про авторів:}

Решетюк Олеся Володимирівна, канд. біол. наук, доцент кафедри ботаніки, лісового і садово-паркового господарства.

Email: o.reshetyuk@chnu.edu.ua

Філіпенко Антоніна Борисівна, канд. біол. наук, доцент кафедри ботаніки, лісового і садово-паркового господарства.

Email: filipter@rambler.ru

Цитування за ДСтУ: Решетюк О. В., Філіпенко А. Б. Барбариси (рід Berberis L.) у декоративному озелененні. Науковий вісник НЛтУ України. 2018, т. 28, № 2. С. 64-67.

Citation APA: Reshetiuk, O. V., \& Filipenko, A. B. (2018). Genus Berberis L. in Decorative Landscaping. Scientific Bulletin of UNFU, 28(2), 64-67. https://doi.org/10.15421/40280211 
2017 pр. за методикою фенологічних спостережень, розробленою для ботанічних садів у період вегетації (Fylypenko, 1979). Вимірювання проводили з кінця березня до другої декади жовтня на дослідних рослинах, інтервал між вимірами становив 7-10 днів, одночасно 3 динамікою росту пагонів відзначали фази фенологічного розвитку рослин. Для вивчення насіннєвого і вегетативного способів розмноження використовували загальноприйняті методики (Davlatov, 2004; Fylypenko, 1979). Енергію проростання і схожість визначали шляхом підрахунку нормально схожих сіянців у встановлені для барбарисів терміни. Під час математичного оброблення отриманих даних використовували методику біометричних розрахунків.

Результати дослідження та їх обговорення. В онтогенезі барбарисів чітко виділяють три періоди: віргінільний (від проростка до дефінітивного етапу), генеративний (статевозрілий) та сенільний. Загальна тривалість віргінільного періоду в аборигенного B. vulgaris не перевищує двох років, тоді як більшість інтродукованих видів завершують його на третій рік життя. Протягом віргінільного періоду барбариси формують декілька наземних пагонів (від 2 до 4) і розвивають розгалужену кореневу систему якірного типу.

Генеративний період у барбарисів визначається разом із формуванням квіток, яке відповідно настає у $B$. vulgaris на третьому, а у більшості інтродуцентів - на четвертому році зростання. Одночасно протягом генеративного періоду збільшується кількість і висота осьових пагонів, які у 15-річному віці відповідно становлять 30-40 шт. і 0,9-3,0 м (залежно від габітусу виду). Одночасно із збільшенням кількості та висоти кущів різко зростає інтенсивність квітування та плодоношення цих рослин. Залежно від погодних умов року ці показники можуть змінюватися в межах 25-30 \%.

Ознаки старіння (початок сенільного періоду) можна спостерігати на прикладі відмирання окремих осьових пагонів, які у більшості барбарисів уже в 10-12-річному віці перестають плодоносити і через 2-4 роки усихають повністю. Однак на інтродукованих у названих вище колекціях видів барбарисів загальний генеративний стан відзначено у віці кущів 27-31 років. За публікаціями науковців, загальна тривалість онтогенезу барбарисів сягає 60-80 років (Davlatov, 2004; Halushko, 1997; Fylypenko, 1979).

Сезонний розвиток барбарисів у культурі теж має специфічні ознаки (табл.). Загальна тривалість вегетаційного періоду більшості видів триває з квітня до середини жовтня, тобто становить 190-200 днів. Тільки $B$. gagnepainii не завершує в умовах місцевого клімату сезонний розвиток, а зупиняє його під впливом понижених температур.

Табл. Феноспектр сезонного розвитку барбарисів

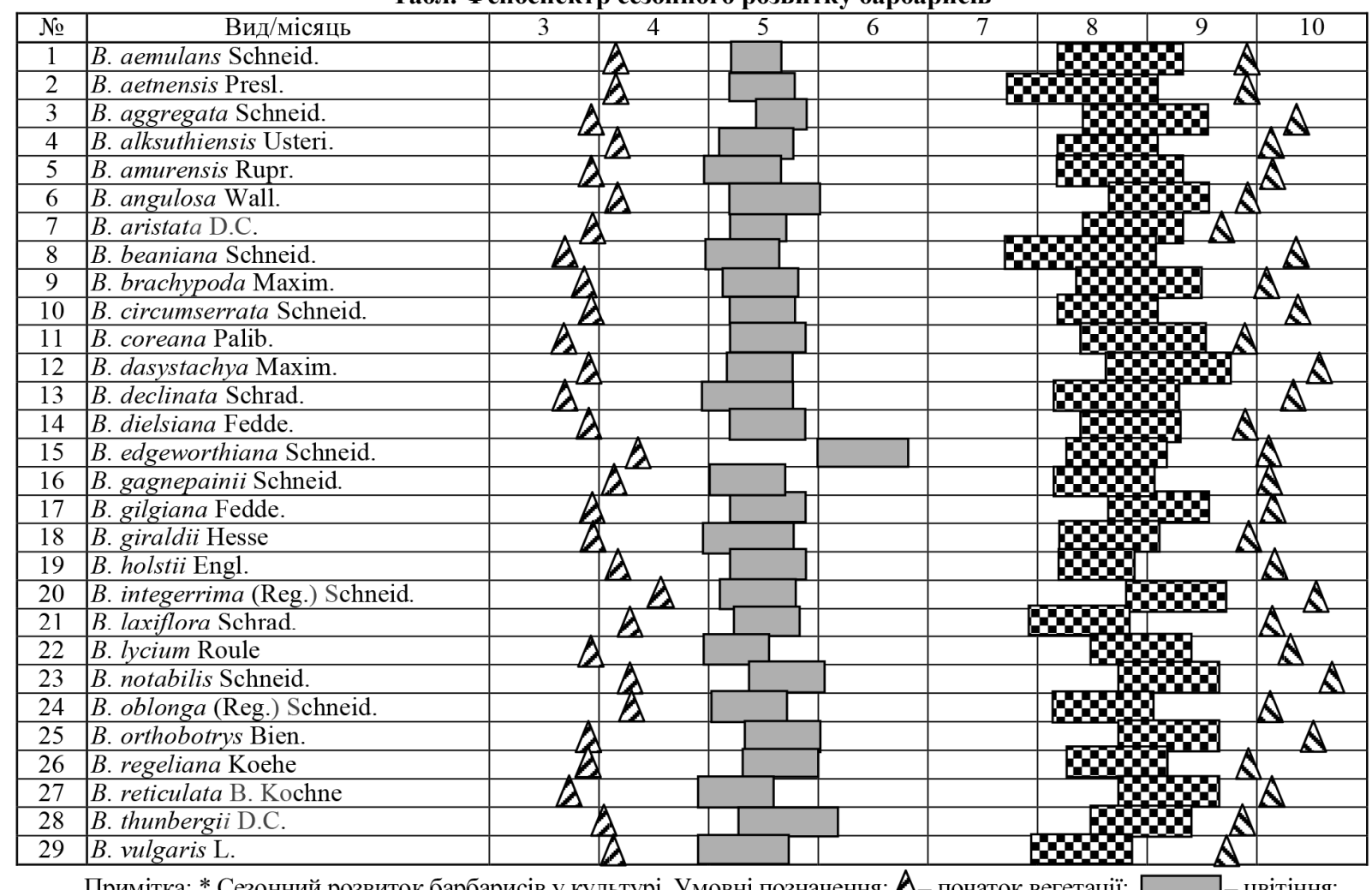

Примітка: * Сезонний розвиток барбарисів у культурі. Умовні позначення: $\boldsymbol{Q}$ - початок вегетації;

$\mathbf{D O A}$ - достигання плодів; $\mathbf{A}$ - кінець вегетації.

Квітують барбариси у травні (за винятком того ж $B$. gagnepainii) впродовж 20-25 днів. У цей час бджоли масово відвідують квітучі барбариси, не менше від квіток гіркокаштана, горобини або малини (рис.). Нектаропродуктивність цих рослин досягає 60-80 кг/га за кожну добу їхнього квітування, а мед 3 компонентами такого нектару відрізняється світло-жовтим кольором та приємним смаком (Vasyleva \& Shreter, 1970; Fylypenko, 1979). Отже, барбариси належать до перспективних видів медодайних рослин і можуть бути використані для розвитку кормової бази бджільництва.

Плоди барбарисів достигають 3 кінця липня (першими - у B. aetnensis і B. beaniana) до кінця серпня (останніми - у B. angulosa, B. dasystachya, B. gilgiana, B. integerrima, $B$. notabilis, а у $B$. orthobotrys - навіть у вересні). Урожайність барбариса в умовах Чернівецької обл. достатньо висока. За нашими оцінками, вона становить протягом перших кількох років генеративного періоду 40-50 плодів/пог.м пагона, а пізніше швидко збіль- 
шується 3 кожним роком. У 10-12-річному віці цей показник для більшості культивованих видів зростає до 350-420 плодів/пог.м пагона. Залежно від погодних умов року, врожайність барбарисів може змінюватись у межах $15-25 \%$.

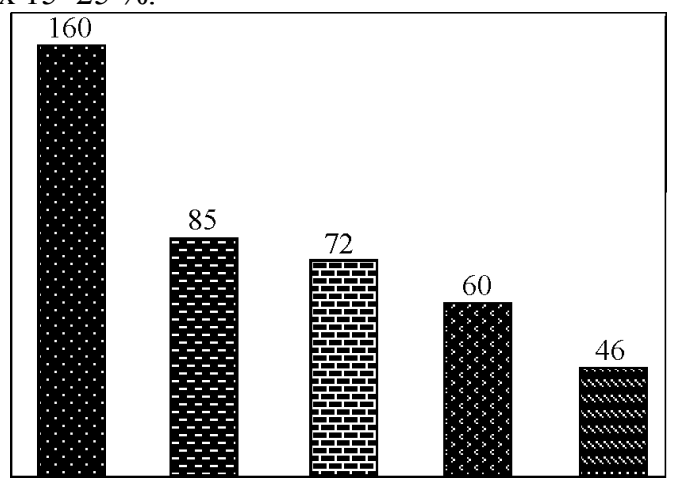

Рис. Інтенсивність відвідування бджолами квітучих рослин (шт./хв на умовні 100 квіток). Умовні позначення: 160) Malus domestica (Borkh.) Borkh.; 85) Aesculus hippocastanum L.; 72) Berberis vulgaris L.; 60) Sorbus aucuparia L.; 46) Rubus idaeus L.

Важливо зазначити цінні харчові властивості плодів барбарисів, які здавна слугували продуктом споживання у багатьох народів Азії. Власне, у Великобританії барбариси почали вирощувати ще 31573 р. разом із агрусом, шипшиною та суницею саме завдяки цінним властивостям його плодів (Palamarchuk \& Bondarenko, 1974). Пізніше і в Росії із плодів барбарисів виготовляли спеціальний пунш, варення, желе, клас питний оцет тощо (Oleksevych, 1972; Palamarchuk \& Bondarenko, 1974). На Кавказі досі плоди барбариса вживають як приправу до м'ясних та овочевих страв, а в сучасній кулінарії з них виготовляють мармелад, морозиво, цукерки та інші види харчових продуктів.

Плоди барбарисів мають не тільки харчове значення, а й значний потенціал для лікування різних захворювань і для профілактики здоров'я (Vasyleva \& Shreter, 1970; Oleksevych, 1972; Palamarchuk \& Bondarenko, 1974; Slyzyk, 1964). Вони є надійним засобом для очищення крові, бо в них містяться глюкоза, фруктоза, яблучна, лимонна та аскорбінова кислоти. Ці плоди використовують для лікування жовтухи, цинги, як жарознижувальний та укріплювальний засоби для діяльності серця та шлунка, а також у разі багатьох інших хвороб. У медицині відомі цілющі властивості й інших видів сировини барбарисів (Vasyleva \& Shreter, 1970; Oleksevych, 1972). Відвар 3 коренів цих рослин вживають для лікування ревматизму та лихоманки, для лікування очей тощо. Листя, кора та недостиглі плоди відзначаються активною кровоспинною дією.

Зимостійкість більшості інтродукованих видів у період 2005-2017 pp. не опускалась нижче I-II балів. Тільки у видів південнокитайського походження (B. dasystachhya i B. arthobotrys) відзначено значне обмерзання пагонів вище від снігового покриву (IV-V бали). Весняні заморозки практично не спричиняють шкоди барбарисам, бруньки яких починають розвиватися тільки наприкінці березня на початку квітня. Розпускання квіток у цих рослин, як зазначено вище, відбувається у травні, коли весняні заморозки в межах Чернівецької обл. практично не проявляються. Осінні заморозки натомість можуть пошкоджувати у жовтні листки у видів південного походження: $B$. aggregata, B. beaniana, B. circumserrata, B. notabilis, $B$. orthobotrys і найбільше $B$. gagnepainii, в якого можуть підмерзати навіть молоді пагони.
Барбариси легко розмножуються в культурі насіннєвим і вегетативним способами. Найпростіше висівати насіння в осінній період. Тоді воно протягом зими перебуває в стані спокою і дружно після цього проростає навесні (схожість такого насіння, за нашими спостереженнями, становить 85-93 \%). Для весняного посіву насіння краще витримати у стані спокою в умовах понижених до $0+5{ }^{\circ} \mathrm{C}$ температур і тоді його схожість сягає $92-$ $95 \%$. Якщо насіння не стратифікувати, схожість знижується більш як вдвічі, а значна частина насіння (до 45 \%) проросте тільки наступного року. На проростки насінного походження, зазвичай, весняні заморозки впливають мало. Виняток становлять тільки названі вище види південнокитайського походження, в яких відзначали ураження верхівок весняними заморозками на 25-30 \%.

Вегетативне розмноження барбарисів зеленими живцями вдається складніше. За нашими оцінками, його краще робити у липні-серпні, коли у рослин завершується період активного росту, але й тоді вкорінити вдається не більше 12-14 \% живців. 3 іншого боку, вирощені з укорінених живців рослини нічим не відрізняються від насінного поновлення за швидкістю росту та розвитку. До того ж поширені в декоративному озелененні строкаті форми барбарисів (переважно у B. vulgaris i $B$. thunbergii) зберігають свої властивості у сіянцях насінного походження, а тому живцювати їх, на нашу думку, немає потреби. В окремих випадках можна використовувати для вегетативного розмноження барбарисів поділ кущів, що забезпечує практично стовідсотковий розвиток усіх відокремлених дочірніх рослин.

Культивування барбарисів може впроваджуватись не тільки для декоративного озеленення територій, а також і для створення спеціалізованих плантацій медодайного або сировинного (лікарського, харчового) призначення. За наведеної вище нектаропродуктивності такі культури здатні за сезон забезпечити до 2,1-2,5 т/га унікального за смаковими та цілющими властивостями меду, що в сучасній грошовій оцінці становитиме близько 1,5 млн грн. Не менш ефектовною може стати й сировина харчового та лікарського призначення (плоди, корені, кора, зелене листя). Загальна кількість рослинної сировини з барбарисової плантації може досягати 3,5-4,2 т/га у сухій вазі, що теж свідчить про економічну ефективність створення таких плантацій.

За матеріалами аналізу біологічних властивостей інтродукованих у Чернівецькій обл. барбарисів, виділено 3 групи видів, перспективних для культивування:

1 група - найперспективніші види ( $B$. angulosa, B. aristata, B. oblonga, B. aemulans, B. aggregata, B. beaniana, $B$. thunbergii);

2 група - перспективні види (B. aetnensis, B. vulgaris, B. spathulata, B. lycium, B. alksuthiensis, B. brachypoda, $B$. circumserrata, $B$. dielsiana, $B$. dasystachya, $B$. gilgiana, $B$. notabilis, $B$. amurensis, $B$. coreana, $B$. regeliana, $B$. reticulata, B. declinata);

3 група - менш перспективні види (B. integerrima, B. edgewortiana, B. giraldii, B. holstii, B. laxiflora, B. orthobotrys).

Висновки. Барбариси в декоративному озелененні мають багато переваг - вони зимостійкі та посухостійкі, швидкорослі, рясно квітують та плодоносять, медодайні та лікарські культури, всі високодекоративні рослини, багато видів газостійкі, невибагливі до грунтових умов, добре переносять міські умови та обрізування тощо. Рекомендації до впровадження барбарисів у деко- 
ративні посадки стосуються створення живоплотів і стрижених бордюрів, формування декоративних груп кущів серед квітників і газонів, обсаджування деревних композицій від галявин і берегів водойм. Потрібно також проаналізувати перспективи культивування барбарисів для створення плантацій господарського спрямування: медодайних, лікарських, харчових. У всіх цих випадках названі види барбарисів можуть бути надзвичайно ефективними у кліматичних умовах України.

\section{Перелік використаних джерел}

Davlatov, S. Kh. (2004). Biologicheskie osobennosti nekotorykh vechnozelenykh vidov roda Berberis L., introdutcirovannykh v Dushanbinskom sadu [Biological features of some evergreen species of the genus Berberis L., introduced in the Dushanbe Garden]. Candidate Dissertation for Biology Sciences. 142 p. [in Russian].

Fylypenko, A. B. (1979). Biologicheskie osobennosti perspektivnykh vidov roda Berberis L., introdutcirovannykh na Bukovine [Biological features of promising species of the genus Berberis L. introduced in Bukovina]. Abstract of Doctoral Dissertation for Biology Sciences (03.00.05 - Botany). Kyiv. 20 p. [in Russian].

Halushko, R. V. (1997). Vidovoe i formovoe raznoobrazie barbarisov $\mathrm{v}$ landshaftnom dizaine [Species and shape diversity of barberry in landscape design]. Informatcionnyi listok, 112-97. Simferopol: Krymskii UNTEI. 4 p. [in Russian].

Oleksevych, V. M. (1972). Barbaris obyknovennyi kak donor i aktceptor fiziologicheski aktivnykh veshchestv [Barbaris ordinary as a donor and acceptor of physiologically active substances]. Fytontsydy. Kyiv: Naukova dumka. [in Russian].

Palamarchuk, A. S., \& Bondarenko, V. B. (1974). O khimicheskom sostave plodov barbarisa obyknovennogo [On the chemical composition of fruits of barberry ordinary]. Rastitelnye resursy, 10(2), 237-238. [in Russian].

Slyzyk, L. Y. (1964). O nekotorykh kriticheskikh vidakh barbarisa iz Srednei Azii [About some critical species of barberry from Central Asia]. Novosti sistematiki vysshikh rastenii, (pp. 79-89). MoscowLeningrad: Nauka. [in Russian].

Vasyleva, V. D., \& Shreter, A. Y. (1970). Sovremennoe sostoianie i perspektivy khimicheskogo izucheniia i meditcinskogo ispolzovaniia barbarisov flory SSSR [Current state and prospects of chemical research and medical use of barberry of the USSR flora]. Nauchnye raboty VNIIDR, 1, 17-21. [in Russian].

Yakobchuk, O. M., \& Kolesnichenko, O. V. (2013). Vykorystannia roslyn vydiv ta kultyvariv rodu Berberis L. pry stvorenni monosadu [Use of plant species and cultivars of the genus Berberis L. in the production of monosodium]. Naukovi dopovidi NUBiP, 1(37). 8 p. Retrieved from: http://www.nbuv.gov.ua. [in Ukrainian].

О. В. Решетюк' А. Б. Филипенко

${ }^{1}$ Черновицкий национальный университет им. Юрия Федьковича, г. Черновиьь, Украина ${ }^{2}$ Восточноевропейский национальный университет им. Леси Украинки, г. Луцк, Украина

\section{БАРБАРИСЫ (РОД ВЕRВЕRIS L.) В ДЕКОРАТИВНОМ ОЗЕЛЕНЕНИИ}

Определены особенности органогенеза и онтогенеза 29 видов рода Berberis L. в культуре (Черновицкая обл.), выявлены различия в прохождении отдельных возрастных периодов развития и общая продолжительность онтогенеза. На основе фенологических наблюдений выделены специфические особенности их сезонного развития в зависимости от географического происхождения. Вегетационный период длится с апреля до середины октября (190-200 дней), цветение - в течение мая, созревание плодов - с июля до конца августа. Установлены потенциальные возможности культивируемых барбарисов в фазах цветения (нектаропродуктивность - до 60-80 кг/га в сутки) и плодоношения (с 40-50 до 350-420 плодов/м пог. побега). Доказано, что высокие показатели и качество нектара (плодов) могут быть успешно использованы в хозяйственных целях (пчеловодство, питание, лечение и т.д.): нектаропродуктивность таких культур обеспечит урожай 2,1-2,5 т/га меда с уникальными вкусовыми и целебными свойствами, а также до 3,5-4,2 т/га сырья лекарственного и пищевого назначения. Проанализирована зимостойкость барбарисов, которая не опускается ниже I-II баллов (у B. dasystachhya и B. arthobotrys побеги могут подмерзать выше снежного покрова). Изучена репродуктивная способность этих видов, они легко размножаются семенами (лучше их высевать осенью). В результате выполненных исследований выделены 3 группы видов, перспективных для культивирования в климатических условиях Буковины, и разработаны рекомендации по внедрению барбарисов в декоративные посадки.

Ключевые слова: интродукция; начало вегетации; культивирование; зимостойкость; декоративность.

O. V. Reshetiuk1, A. B. Filipenko ${ }^{2}$

${ }^{1}$ Yuriy Fedkovych Chernivtsi National University, Chernivtsi, Ukraine ${ }^{2}$ Lesya Ukrainka Eastern European National University, Lutsk, Ukraine

\section{GENUS BERBERIS L. IN DECORATIVE LANDSCAPING}

The authors have fixed organogenesis and ontogenesis features of 29 Berberis species at culture (Chernivtsi region). Genus Berberis L. of Berberidaceae Juss. family conyains nearly 175 species and has various vital forms such as trees, shrubs and perennial grasses. They are common in Europe, North Africa, North and South America, Middle Asia and Caucasus. The center of its genus area is China-Tibet plant-climate region. There is only one species in Ukraine, Berberis vulgaris L., which grows in Crimean Mountains, the Dnepr and the Dnister valleys. We have discovered the differences in special age periods of development and common ontogenesis durability of this species. We have also distinguished three periods in barbarizes ontogenesis: virgin (from sprout till definitive stage), generative (sexual) and old. Virgin period of $B$. vulgaris lasts from two to three years of most introduced species. Generative period begins with the first flowering of these plants (B. vulgaris - on the third, introduced species - on the fourth year). Flowering and fruiting intensity depends on the year weather within the limits of $25-30 \%$. We have analyzed winter resistance and reproductive capabilities of this species. First signs of old could be fixed at 10-12 year of axial shoots; they finished flowering and after 24 year died off fully. But in general barbarizes ontogenesis continues for 60-80 years in general. We have distinguished some specific peculiarities of seasonal development depending on geographical origin. The authors have also determined potential possibilities at flowering and fruiting phases of barbarizes in culture, analyzed those nectars and fruiting productions, which would be at household use (beekeeping, foodstuff, treatment). As a result of forged investigations we have defined 3 groups of species, which will be perspective for cultivation in Bukovina climatic conditions. Our recommendations for barbarizes in culture are as follows: these plants are the best for hedges, borders and decorative groups among flowerbeds or lawns, for planting near lakes or glades. They can be used for honeyed, medical and food-producing plantation as well.

Keywords: introduction; beginning of vegetation; cultivation; winter resistance; decoration. 